4 Ippoliti, A F, et al, Gastroenterology, 1978, 74, 393.

5 Saunders, J H B, and Wormsley, K E, Lancet, 1977, 1, 765.

6 Bodemar, G, and Walan, A, Lancet, 1978, 1, 403.

${ }^{7}$ Blackwood, W S, et al, Gut, 1977, 18, A420.

${ }^{8}$ Longstreth, G F, et al, New England fournal of Medicine, 1976, 294, 801

${ }^{9}$ Gray, G R, et al, Gastroenterology, 1978, 74, 3987.

10 Gudmand-Høyer, E, et al, British Medical fournal, 1978, 1, 1095.

11 Langman, J M S, Symposium on Management of Peptic Ulceration, Royal College of Surgeons of Edinburgh, April 1978

12 Wormsley, K G, Symposium on Management of Peptic Ulceration, Royal College of Surgeons of Edinburgh, April 1978.

${ }^{13}$ Hetzel, D, D, Symposium on Management of Peptic Ulceration, Royal College of Surgeons of Edinburgh, April 1978.

14 Wallace, W A, Orr, C M E, and Bearn, A R, British Medical fournal, 1977, 2, 865 .

15 Hoste, P, et al, Lancet, 1978, 2, 666.

16 Forrest, J A H, Symposium on Management of Peptic Ulceration, Royal College of Surgeons of Edinburgh, April 1978.

17 Hall, W, New England fournal of Medicine, 1976, 295, 841.

18 Blackwood, W S, et al, Lancet, 1976, 2, 174.

19 Delle Fave, G F, et al, Lancet, 1977, 1, 1319.

${ }^{20}$ Witzel, L, et al, Gastroenterology, 1977, 73, 797.

${ }^{21}$ Avella, J, et al, Lancet, 1978, 1, 624

\section{Hazards of epilepsy}

Bland words of reassurance do little to relieve the anxiety of parents fearful that a fit during sleep may kill their epileptic child. Familiarity with recurrent fits may eventually give them confidence-as they believe that the next fit will be as stereotyped and innocuous as the last. Some parents, however, do not get over the shock of witnessing the first convulsion, convinced that their child-apnoeic, stiff, and cyanosed-was dying; and it may lead to such a degree of watchful overprotection that epilepsy comes to dominate the life of the family.

A divided nightly vigil shared by parents is perhaps the extreme variant of this fear, but some worry about suffocation in a nocturnal fit is common, especially in parents of the very young. This may lead them to install a baby alarm, or share the same bed (usually with the willing collusion of the child, whose demanding behaviour may reflect the exceptional indulgence which parental anxiety breeds). This anxiety-and the restrictions of freedom which it generates-must be seen as counterproductive. Though difficult to measure, psychosocial factors are widely believed to influence the frequency and character of fits in children (as in adults), and in many children there appears to be a vicious circle of parental anxiety and poor control of fits. Yet much of our medical advice serves to consolidate rather than relieve these difficulties-for example, the recommendation of anticonvulsant medication is sometimes bolstered by the threat of brain damage through noncompliance, and swimming and cycling may be forbidden because of the harm that might accompany a fit occurring in potentially hazardous circumstances.

How valid are these well-intentioned but frustrating restrictions? Most studies of comparative risk rates for drowning, suffocation in bed, or trauma in patients with epilepsy have been based on patients in long-stay hospitals or mental subnormality units and have not included corrections for differing policies of management. ${ }^{1-4}$ Simply because so many epileptics are dissuaded from swimming and driving, statistics of drowning and of road traffic accidents cannot identify the size of the potential hazard. Nevertheless, what evidence we have suggests that misadventure is relatively rare.

For example, the Brisbane Drowning Study ${ }^{3}$ showed that, though the risk of drowning was four times greater in epileptic children who swam than in normal children, the absolute risk remained low. ${ }^{6}$ Among the 107 deaths at all ages in the 10-year review of patients at the Norwegian State Hospital for Epilepsy and in the neurological unit of the University of Oslo three were due to accident and 11 to drowning. ${ }^{2}$ Other $w$ population studies have shown few or no excess deaths due to epilepsy except in those patients (mostly children) who are mentally or physically handicapped, ${ }^{7}$ who tend to have more $c$ severe epilepsy anyway. At a children's psychiatric hospital ${ }^{1} \ddot{\Rightarrow}$ there was no difference in the rate of injury among epileptic $\stackrel{\text { ? }}{+}$ and non-epileptic children "engaged in a full athletic programme" $\left(2.9 \%\right.$ and $2.8 \%$ respectively). From the infrequency $\frac{\bar{\sigma}}{\bar{\omega}}$ of reports of death during sleep ${ }^{8}$ apparently due to suffocation $\vec{\nabla}$ during a fit the hazard may be presumed rare-especially in comparison with the frequency of nocturnal fits in children. क

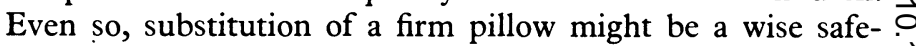
guard.

Generally, therefore, the picture is reassuring. Most of the traditional restrictions on epileptics, though well justified in $\frac{5}{3}$ theory, can be waived in practice, though not entirely abandoned. The enlightened medical director of the largest residential school in Britain for children with epilepsy has $N$ encouraged building a swimming pool at his school, arguing $\vec{A}$ that the need to be able to swim is even greater for his pupils than for others. Swimming under supervision should be possible for all but the most poorly controlled patients. $\omega$ Nevertheless, for bathing a shower is preferable to the bath- $\complement$ tub for those children who demand privacy.

Cycling, too, is permissible for children with well-controlled $\vec{\bullet}$ fits or with "situation-dependent" or nocturnal attacks, if they have access to uncluttered highways. Sadly, for many (including normal) children this is an almost unattainable ideal in large conurbations. What constitutes good control of fits is an arbitrary judgment. Important factors in the decision whether or not to discourage cycling include not only the frequency $\stackrel{\mathbb{Q}}{\Omega}$ of fits but also the amount of warning. School teachers often $\overrightarrow{\vec{A}}$ need guidance as much as parents. Their fearful prejudices $\exists$ may be unnecessarily restrictive, and they need an enlightened view of the management of epilepsy with a willingness to include rather than exclude sufferers in school activities.

\section{${ }^{1}$ Aisenson, M R, Pediatrics, 1948, 2, 85. \\ 2 Krohn, W, Epilepsia, 1963, 4, 315. 1960. $1954,156,1526$ \\ 6 Pearn, J S, British Medical fournal, 1977, 1, 1510 Worcester-Drought, C, Lancet, 1970, 2, 876 \\ Epidemic myalgic encephalomyelitis}

${ }^{3}$ Lennox, W G, Epilepsy and Related Disorders, vol 2. London, Churchill,

${ }^{4}$ Schwade, E D, and Otto, O, fournal of the American Medical Association, 5 Pearn, J H, Nixon, J, and Wilkey, I, Medical fournal of Australia, 1976,
2, 942 .

${ }^{7}$ Livingston, S, Living with Epileptic Seizures. Springfield, Thomas, 1963.

Outbreaks of the paralytic disease known as epidemic myalgic encephalomyelitis have puzzled doctors all over the world in the past 30 years. One of the best known of these epidemics was that at the Rnyal Free Hospital in London in 1955, which affected more than 300 people. ${ }^{1}$ Most outbreaks tend to occur in the summer, young adults are predominantly affected, and the incidence is higher in women. The evidence suggests that infection is spread by personal contact, and young hospital personnel seem particularly at risk. The features common to 